\title{
The Efficacy of Ringer lactate and Sublingual Nitrates vs Indomethacin to Reduce Post-ERCP Pancreatitis: A Review Article

\author{
AlAmri Turki Abdullah
}

\author{
Division of Gastroenterology, Department of Internal Medicine, King Fahad Hospital University, Imam Abdulrahman \\ Bin Faisal University, Dammam 31441, Saudi Arabia \\ Corresponding author: AlAmri Turki Abdullah, Mobile: +966557521347, E-mail: taalamri@iau.edu.sa
}

\begin{abstract}
Background: Inflammation in pancreas usually happens as a complication after endoscopic retrograde cholangiopancreatography (ERCP) in 16\% from patients. Many studies confirmed this incidence rate of pancreatitis. Some special intervention pre-, post-operative and also during may decrease the incidence rate of pancreatitis after cholangiopancreatography, as well as mortality rate. Proper history taking and physical examination about risk factors of procedure related risks may help in determining the proper patients. Most post-endoscopy pancreatitis (PEP) complications are mild to moderate inflammation only. The defined pathophysiology of PEP is initially damaged activation of drainage of duct of pancreas which secrets phospholipase A2, then prostaglandin, and prostacyclin then finally, ischemic attack for pancreatic cells.
\end{abstract}

Objectives: This study aimed to compare between the efficacy of Ringer lactate and sublingual nitrates vs indomethacin to reduce post-ERCP pancreatitis

Methods: The databases were searched for articles published in English in 3 data bases [PubMed, Google scholar and science direct]. Post-ERCP Pancreatitis (and, or, not) had been used such as [Ringer lactate and sublingual nitrates vs indomethacin] and in peer-reviewed articles between January 2008 and October 2020.

Results: There're some pharmaceutical actions using pharmacological agents that may help in preventing post-operative or after endoscope inflammation of pancreas. Latest information suggested ringer lactate and sublingual nitrates to decrease the danger of post-endoscopic retrograde cholangiopancreatography pancreatitis (post-ERCP) in vulnerable group. Another data added that pancreatic stents may benefit in preventing this problem.

Conclusion: A blend of ringer lactate with sublingual nitrate is substantially more effective compared to indomethacin without help from anyone else in view of the assurance against pancreatitis following ERCP.

Keywords: ERCP, Post-ERCP pancreatitis, Endoscopic retrograde cholangio-pancreatography, Ringer lactate, Sublingual nitrates, Indomethacin.

\section{INTRODUCTION}

Inflammation in pancreas usually happens as a complication after endoscopic retrograde cholangiopancreatography, in $16 \%$ of patients. Many studies confirmed this incidence rate pf pancreatitis. Some special intervention pre-, post-operative and also during may decrease the incidence rate of pancreatitis after cholangiopancreatography, as well as mortality rate. There is .4 to $.6 \%$ of patients may complicated with severe pancreatitis. Most complication that occurs after PEP is mild to moderate inflammation only. The defined pathophysiology after PEP is initially damaged activation of drainage of duct of pancreas which secrets phospholipase A2, then prostaglandin, and prostacyclin then finally, ischemic attack for pancreatic cells. A great deal of methods is recommended for halting post-ERCP pancreatitis, and also might be classified to stenting of pancreatic duct together with pharmacological prophylaxis. Pancreatic duct stenting occurs due to damaged drainage of pancreas via its duct that may occur due to papillary edema or perhaps stenosis of the oddi sphincter all through ERCP. Affected by previous scientific tests, the great bulk of endoscopists invest a "fall out" stent in the pancreatic duct in vulnerable groups ${ }^{(1)}$.
The practical usage of non-steroidal antiinflammation drugs rectally as prophylactic for PEP has similarly been confirmed in conducted studies. Today, healthcare information confirmed significantly that the usage of non-steroidal anti-inflammatory medications to solve/prevent PEP may be beneficial. The NSAIDs stop a number of inflammatory mediators of cascade, which are considered to possess role in the disease process of acute pancreas inflammation, particularly, prostaglandins in addition to phospholipase A2. For an end result, $100 \mathrm{mg}$ of indomethacin rectally instantly before or perhaps post ERCP is recommended for proper protection and to reduce the possibility of inflammation for vulnerable groups of PEP. Nitrates may possess considerable impact in prevention of postERCP pancreatitis as well (2).

The impact of adequate IV administration of lactated Ringer's solution has similarly been established in probably the latest scientific tests to decrease PEP. Most trials, which happen to examine the convenience of PD stenosis in vulnerable groups, which at too much risk of PEP are created just before these pharmacological measures began being available ${ }^{(3,4)}$.

Nitrates protect from post-ERCP pancreatitis. The impact of sublingual nitrates to decline post-ERCP 
pancreatitis was examined in 3 Meta analyses, of which 2 indicated the nitrates protective impact ${ }^{(5,6)}$.

The goal of the analysis was looking at the impact of pharmacological protection through the use of sublingual nitrates as well as ringer lactate vs utilizing indomethacin in the protection against PEP.

\section{Literature Review: \\ Ringer Lactate:}

Significantly, intravenous (IV) lactated ringers were dissected as possible prophylactic against postERCP pancreatitis. Lactated ringer 'LR' is an appropriate crystalloid decision combined with lactate of 20-8 mEq, which is changed into sodium bicarbonate quickly within hepatic cells as well as its good idea for helping every serum additionally as $\mathrm{pH}$ within acinar cells. Increased intra-acinar $\mathrm{pH}$ is found to build the base highlight pancreatitis limiting force in numerous preliminaries ${ }^{(7)}$.

Beginning IV organization in administration of intense aggravation of pancreas is recommended by clinical practice guidelines. The 2 broadly sold hydration cures put on to start administration of intense aggravation of pancreas are lactated Ringer's and saline arrangement (NSS). Early IV organization with LRS is displayed to lessen the occurrence of foundational provocative effect condition when contrasted and past hydration with NSS ${ }^{(8)}$.

A recently available preliminary led by Buxbaum whenever driven per procedural IV organization with lactated Ringer fix decreased the shot at PEP. People was haphazardly assigned (2:1) getting IV organization with lactated Ringer arrangement or possibly may be standard hydration with the indistinguishable fix. They discovered that not among individuals in the determined hydration type created PEP, though $17 \%$ of individuals in the customary hydration partner created PEP. There's not really any proof of volume expanded burden in these individuals, implying that determined IV organization of lactated Ringer arrangement may easily decrease the treatment phases of PEP ${ }^{(9)}$.

Xiong et al. ${ }^{\left({ }^{10)}\right.}$ stated that a huge decrease within the post-ERCP pancreatitis incidence in individuals pretreated using gabexate mesylate (nonstop IV imbuement of $300 \mathrm{mg}$ of gabexate mesylate blended with $500 \mathrm{cc}$ Ringer lactate recipe all through $111 \mathrm{~mL} / \mathrm{h}$, initiating with 30 minutes prior to the process and proceeding for nearly 4 hours following the process) compared to fake treatment. The outcomes recommended 4 and half hours of gabexate mesylate may stop post-ERCP pancreatitis. In addition, preliminaries in creature's models of aggravation of pancreas have discovered that lactate only lessens pancreatitis and most certainly the severity of irritation of pancreas.

Besides, individuals are typically fasting and thusly might be somewhat got dried out just before their measure. Unquestionably, research recommends that, a peri-procedural uplifted BUN, is an indication of hemoconcentration as well as drying out, and has been connected with upgrade of post-ERCP pancreatitis not withstanding its power ${ }^{(\mathbf{1 0}, \mathbf{1 1})}$.

Loads of studies assessed 8-24-hours conventions of lactated ringer to stop post-ERCP pancreatitis ${ }^{(9)}$. A bigger multicenter follow-up randomized controlled trial contrasted outrageous hydration with lactated ringer prior to, within, as well as 8 hours following the technique to conventional hydration applying the method in 510 individuals with a local papilla inside three tertiary reference administrations within Korea. Their review discovered that, concentrated hydration along with the likelihood was brought by LR likewise down to reality of PEP ${ }^{(12)}$. A followed meta examination like as 7 planned clinical preliminaries taking a gander at outrageous hydration assirted that escalated hydration altogether diminished the danger of PEP; in any case, study fluctuated in their regimens worn also their definitions ${ }^{(\mathbf{1 3})}$.

\section{Sublingual Nitrates:}

Sort of prescription called nitrates is an amazing muscle relaxant medication thought to encourage pancreatic blood stream just as abatement stenosis and sphincter strain of Oddi. Today, diminished information regarding the utilization of nitrates, with various fake treatments in randomized controlled trials (RCTs) is revealing a critical decrease in the shot at $\operatorname{PEP}^{(14,15)}$. The consequence of sub-lingual nitrates on decrease of postERCP pancreatitis has been analyzed in various other investigations as well ${ }^{(6)}$. Numerous one more various examinations on randomized controlled trials have discovered that, nitrates could lessen danger of postERCP pancreatitis with meta-investigation that exhibited a sizable risk minimization using sub-lingual nitrates ${ }^{(2,16)}$. Albeit the impact of sublingual course of organization of nitrates, which has a higher assimilation level for the avoidance of PEP is set up by metaexamination, effective organization of nitrates by skin course, alongside that is the ideal course of organization, didn't arrive at factual importance for the counteraction of PEP ${ }^{(6)}$. Numerous preliminaries of RCTs have analyzed the aftereffect of nitrates on PEP. Large numbers of these tests displayed a critical decrease in PEP, while another people showed no advantage ${ }^{(15,17)}$.

Effective organization of nitrates on skin had been yielded differing results, with 3 RCTs displaying no utilization alongside 1 after an astounding result. One RCT looking at the capacity of IV nitrates in stopping PEP in moderate to vulnerable gatherings ended too early because of a between time investigation implying pointlessness and furthermore a disturbing recurrence of undesirable hemodynamic meetings (25). An 
assortment of meta-examinations have displayed around $30 \%$ - 40\% decline in hazard about the utilization of nitrates in the insurance against PEP ${ }^{(6,18,}$ 19)

Primarily in light of the fact that nitrates is proposed to work by decreasing the strain, not really set in stone whether it will offer gradual been match of pancreatic stent arrangement. By and by, sublingual nitrates may have an assignment in diminishing possibility circumstances, inside asset restricted conditions, or maybe rather than pancreatic stent addition. A current little relative strength RCT exhibited that combining sublingual nitrates with indomethacin rectally was worked on in contrast with indomethacin in an assessment test for the most part, which didn't accept the pancreatic stents ${ }^{(20)}$. Another multicenter RCT with different methodology is altered for affirming accommodation of sublingual nitrates as well as rectally admitted indomethacin in proper patients' populace (hazard circumstances that are high in places where stenting isn't generally accessible).

Nitrates are orally regulated and consequently are reasonable alongside as of late available investigation shows they might give extra advantage of indomethacin. They're not utilized right now in medical care practice basically as a result of the danger of hypotension.

\section{Combination between ringer lactate and sublingual nitrates:}

Sotoudehmanesh et al. (20) evaluated mix of administration of rectally indomethacin in addition to sublingual nitroglycerin in the protection against PEP, with others vulnerable which is significant for postERCP pancreatitis in the mind. In that specific doubleblinded randomized controlled trial, '300' people were selected to administer with rectally admitted indomethacin of $100 \mathrm{mg}$ coupled with sublingual nitrates of $5 \mathrm{mg}$, or perhaps indomethacin of $100 \mathrm{mg}$ prior to ERCP. They observed that, costs of post-ERCP pancreatitis getting considerably reduced in patients, which received blend indomethacin nitrates therapy unlike the indomethacin placebo cohort.

Keep in mind that a large portion of the study participants didn't put stents within the pancreatic duct. They recognized that, conjunction of treatment by indomethacin administration in addition to sub-lingual nitroglycerin prior to the ERCP had more likelihood to bring down chance of post-ERCP pancreatitis, in comparison with indomethacin rectally admitted remedy by itself. Generally there was no damage attributable to the pharmacological prevention or maybe perhaps bodily prophylaxis (PD stenting) at each person. Generally there were no deaths connected to PEP (20). Nitrates have not yet made their way into guidelines ${ }^{(21)}$; however, they should be considered adjunctive therapy to rectal NSAIDs in valnerable groups that do not take a prophylactic stent.

\section{NSAIDS and Indomethacin:}

Different researchers in their studies examined actions of prophylaxis of pharmacological and nonpharmacological preparations especially in the period of 5 years between 2003 to 2008. Additional RCTs of administration of decreased dose of rectally diclofenac plus somatostatin as well as mix of indomethacin with sublingual nitrates have been established. On the basis of available data, administration of rectally NSAIDs (hundred $\mathrm{mg}$ diclofenac or perhaps indomethacin instantly before or maybe following ERCP) might be recommended for people having higher threat ERCP. Vice versa remains about the function of NSAIDs in non-vulnerable groups ${ }^{(22)}$. Nevertheless, proper electrical clinical study in non-vulnerable groups will involve an incredibly huge sample size. In light of the truly affordable regarding 1 helping of NSAIDs, the incredibly convenient protection profile and prior metaanalyses hinting it is equally as helpful in very low risk situations, time in addition to information necessary to conduct a definitive RCT may not be justified ${ }^{(23,24,25)}$.

Lots of controlled studies have determined the impact of administration of rectally indomethacin in the protection against PEP. As an end result, regime rectal $100 \mathrm{mg}$ of indomethacin instantly before or perhaps after ERCP is recommended for reducing the risk of PEP in vulnerable groups. In a recently accessible society meta-analysis, rectal NSAIDs were discovered by Akbar et al. ${ }^{(26)}$ getting much better compared to PD stenting for the protection against PEP.

Elmunzer et al. ${ }^{(23)}$ selected 602 people randomized to receive individual serving rectal $100 \mathrm{mg}$ of indomethacin or perhaps placebo immediately after ERCP. The costs of PEP in individuals treated by NSAID as well as placebo using people were $9.2 \%$ together with $16.9 \%$, respectively. The rates of moderate to severe inflammation of pancreas inside Placebo-treated individuals as well as NSAID-treated individuals were $4.4 \%$ together with $8.8 \%$, respectively ${ }^{(26)}$.

Levenick et al. ${ }^{(27)}$ conducted research provided, prospective, double blind, placebo-controlled study analyzing the efficacy of prophylactic indomethacin use for all those people undergoing ERCP, similar to all those at common danger for PEP. The trial included 449 consecutive individuals that underwent ERCP from March one, 2013, During the task, participants were randomized in a 1:1 way being occasionally 1 helping of $100 \mathrm{mg}$ of indomethacin rectally $(\mathrm{n}=223)$ or perhaps a placebo suppository, with the enhancement of PEP as the key end point (defined as revolutionary upper abdominal pain, 3xULN elevation of lipase quantities, and the hospitalization after ERCP for 2 consecutive 
nights). Sixteen people $(7.2 \%)$ in the indomethacin cohort as well as $11(4.9 \%)$ in the placebo cohort proceeded to get PEP, which was not significant ${ }^{(27)}$.

Over the most recent ten years, concentrate on zeroing on the prophylactic effect of rectally regulated nonsteroidal calming drugs (NSAIDs) has given reestablished desire to PEP pharmacoprevention. Great meta-investigations of exploratory preliminaries of rectal diclofenac just as indomethacin brought about a grade an idea for the utilization of these pills by the European Society for Gastrointestinal Endoscopy, alongside the accompanying huge scope, methodologically strenuous RCT has caused further developed acknowledgment of rectal NSAIDs in clinical practice $^{(4,23,28,29,30)}$.

Notwithstanding the organization of prophylactic pancreatic stents, PEP reliably impact $10 \%-15 \%$ of people at expanded danger. Because of the sizable horribleness, surprising mortality, and costs, which are high, connected with PEP, extra examination is crucial for additional reduction of the probability of the issue. To this end, there are as of now various steady, enlisted PEP pharmacoprevention RCTs ${ }^{(31,32,33)}$.

\section{CONCLUSION}

Standard utilization of rectal indomethacin of all people going through ERCP eliminates the risk of PEP. Pancreatic channel stents diminish the danger of PEP in high danger individuals. There's arising data that extreme hydration with lactated Ringer's and nitrates may furthermore diminish PEP. Sublingual nitrate could offer additional benefit to ringer lactate in halting PEP.

To the absolute best of the information on our own, this is the absolute first investigation which shows a favorable effect of mix of sublingual nitrates and ringer lactate for the security against PEP as opposed to NSAIDs (indomethacin) on its own especially in people in danger that is high for PEP.

To summarize, a blend of ringer lactate with sublingual nitrate is substantially more effective compared to indomethacin without help from anyone else in view of the assurance against pancreatitis following ERCP. Albeit potential multicenter studies are needed to confirm the discoveries of our own. This examination raises suggestions for more review to learn approaches to decrease the speed of PEP in these people (e.g., look at the combination of ringer lactate + nitrates versus indomethacin $+\mathrm{PD}$ ).

\section{Future Recommendations:}

Pharmacological prophylaxis is a significant component of post ERCP pancreatitis (PEP) assurance. Various pharmacological specialists are inspected in PEP prophylaxis. The writing audit would look at the adequacy of numerous pharmacological specialists in the insurance against PEP, the course of theirs of organization, and furthermore the right planning of organization. The ideal medications for the insurance against PEP is alluring to continue to follow models: (I) powerful; (ii) simple to utilize; (iii) not costly; (iv) individual use; and furthermore (v) secure ${ }^{(34)}$.

The confirmation for nitrate viability is moderate and it isn't prompted for PEP prophylaxis. By the by, sublingual nitrates give you a potential prophylactic decision in people with contraindications to NSAIDs. Further logical investigations in the long haul can assist with deciding the work of sublingual nitrates in PEP prophylaxis clearly.

NSAIDs are reasonable, being sold, alongside fruitful in PEP avoidance; in this manner, they should be used in many people at exorbitant danger of creating PEP, if they don't have a few problems which could block the utilization of its. Rectal NSAIDs, related to intravenous hydration, are an extra useful alternative which could be used in high danger individuals. There's little proof to consider the utilization of prophylactic rectal NSAIDs in lower to direct danger people. Extra examinations in such manner may be a possible piece of examination as long as possible.

\section{Financial support and sponsorship: Nil. Conflict of interest: Nil.}

\section{REFERENCES}

1. Fan J, Qian J, Wang Y et al. (2015): Updated metaanalysis of pancreatic stent placement in preventing postendoscopic retrograde cholangiopancreatography pancreatitis. World J Gastroenterol., 21: 7577 - 7583.

2. Hao J, Wu D, Wang Y et al. (2009): Prophylactic effect of glyceryl trinitrate on post-endoscopic retrograde cholangiopancreatography pancreatitis: a randomized placebo-controlled trial. World J Gastroenterol., 15: 366 -368 .

3. Shaygan-Nejad A, Masjedizadeh A, Ghavidel A et al. (2015): Aggressive hydration with lactated Ringer's solution as the prophylactic intervention for postendoscopic retrograde cholangiopancreatography pancreatitis: a randomized controlled double-blind clinical trial. J Res Med Sci., 20: 838 - 843.

4. Elmunzer B, Scheiman J, Lehman G et al. (2012): A randomized trial of rectal indomethacin to prevent postERCP pancreatitis. N Engl J Med., 366: 22-1414.

5. Shao L, Chen Q, Chen $M$ et al. (2010): Nitroglycerin in the prevention of post-ERCP pancreatitis: a metaanalysis. Dig Dis Sci., 55: 1-7.

6. Chen B, Fan T, Wang C (2010): A meta-analysis for the effect of prophylactic GTN on the incidence of postERCP pancreatitis and on the successful rate of cannulation of bile ducts. BMC Gastroenterol., 10: 85.

7. Takacs T, Rosztoczy A, Maleth J et al. (2013): Intraductal acidosis in acute biliary pancreatitis. Pancreatology, 13(4): 5-333.

8. Wu B, Hwang J, Gardner T et al. (2011): Lactated Ringer's solution reduces systemic inflammation compared with saline in patients with acute pancreatitis. Clin Gastroenterol Hepatol., 9: 710-717. 
9. Buxbaum J, Yan A, Yeh K et al. (2014): Aggressive hydration with lactated Ringer's solution reduces pancreatitis after endoscopic retrograde cholangiopancreatography. Clin Gastroenterol Hepatol., 12: 303-307.

10.Xiong G, Wu S, Zhang X et al. (2006): Clinical trial of gabexate in the prophylaxis of post-endoscopic retrograde cholangiopancreatography pancreatitis. Braz J Med Biol Res., 39:85-90.

11.de Madaria E, Herrera-Marante I, GonzalezCamacho V et al. (2018): Fluid resuscitation with lactated Ringer's solution vs normal saline in acute pancreatitis: a triple-blind, randomized, controlled trial. United European Gastroenterol J., 6 (1): 63-72.

12. Choi J, Kim H, Lee $B$ et al. (2017): Vigorous periprocedural hydration with lactated ringer's solution reduces the risk of pancreatitis after retrograde cholangiopancreatography in hospitalized patients. Clin Gastroenterol Hepatol., 15 (1): 86-92.

13.Zhang Z, Duan Z, Wang L et al. (2017): Aggressive hydration with lactated ringer solution in prevention of postendoscopic retrograde cholangiopancreatography pancreatitis: a meta-analysis of randomized controlled trials. J Clin Gastroenterol., 5 1(3):17-26.

14. Elmunzer B (2017): Combination pharmacoprophylaxis for post-ERCP pancreatitis: working toward an evidence base. Gastrointest Endosc., 85 (5): 6-1014.

15. Bhatia V, Ahuja V, Acharya S et al. (2011): A randomized controlled trial of valdecoxib and glyceryl trinitrate for the prevention of post-ERCP pancreatitis. $\mathrm{J}$ Clin Gastroenterol., 45 (2): 170-176.

16. Lyu Y, Wang B, Cheng Y et al. (2020): Comparative efficacy of 9 major drugs for postendoscopic retrograde cholangiopancreatography pancreatitis: a network metaanalysis. Surg Laparosc Endosc Percutan Tech., 29 (6): 32-426.

17. Beauchant $M$, Ingrand $P$, Favriel $J$ et al. (2008): Intravenous nitroglycerin for prevention of pancreatitis after therapeutic endoscopic retrograde cholangiography: a randomized, double-blind, placebocontrolled multicenter trial. Endoscopy, 40: 631636.

18. Bai Y, Xu C, Yang X et al. (2009): Glyceryl trinitrate for prevention of pancreatitis after endoscopic retrograde cholangiopancreatography: a meta-analysis of randomized, double-blind, placebocontrolled trials. Endoscopy, 41: 690-695.

19.Ding J, Jin X, Pan Y et al. (2013): Glyceryl trinitrate for prevention of post-ERCP pancreatitis and improve the rate of cannulation: a meta-analysis of prospective, randomized, controlled trials. PLoS One, 8: 75645.

20.Sotoudehmanesh R, Eloubeidi M, Asgari A et al. (2014): A randomized trial of rectal indomethacin and sublingual nitrates to prevent post-ERCP pancreatitis. Am J Gastroenterol., 109: 903-909.

21. Dumonceau J, Andriulli A, Elmunzer B et al. (2014): Prophylaxis of post-ERCP pancreatitis: European
Society of Gastrointestinal Endoscopy (ESGE) Guideline - updated June. Endoscopy, 46 (9): 799-815.

22. Khoshbaten M, Khorram H, Madad L et al. (2008): Role of diclofenac in reducing post-endoscopic retrograde cholangiopancreatography pancreatitis. J Gastroenterol Hepatol., 23: e11-e16.

23. Elmunzer B, Waljee A, Elta G et al. (2008): A metaanalysis of rectal NSAIDs in the prevention of postERCP pancreatitis. Gut, 57: 1262-1267.

24.Dumonceau J, Rigaux J, Kahaleh M et al. (2010): Prophylaxis of post-ERCP pancreatitis: a practice survey. Gastrointest Endosc., 71: 934-939.

25.Sethi S, Sethi N, Wadhwa V et al. (2014): A metaanalysis on the role of rectal diclofenac and indomethacin in the prevention of postendoscopic retrograde cholangiopancreatography pancreatitis. Pancreas, 43: 190-197.

26. Akbar A, Abu Dayyeh B, Baron T et al. (2013): Rectal nonsteroidal anti-inflammatory drugs are superior to pancreatic duct stents in preventing pancreatitis after endoscopic retrograde cholangiopancreatography: a network meta-analysis. Clin Gastroenterol Hepatol., 7: $778-783$.

27.Levenick J, Gordon S, Fadden L et al. (2016): Rectal indomethacin does not prevent post-ERCP pancreatitis in consecutive patients. Gastroenterology, 150 (4): 911917.

28.Dumonceau J, Andriulli A, Deviere J et al. (2010): European Society of Gastrointestinal Endoscopy (ESGE) guideline: prophylaxis of post-ERCP pancreatitis. Endoscopy, 42: 503-515.

29.Sun H, Han B, Zhai H et al. (2014): Rectal NSAIDs for the prevention of post-ERCP pancreatitis: a metaanalysis of randomized controlled trials. Surgeon, 12 (3): 141-147.

30.Hanna M, Portal A, Dhanda A et al. (2014): UK wide survey on the prevention of post-ERCP pancreatitis. Frontline Gastroenterol., 5: 103-110.

31.Hauser G, Milosevic M, Giljaca V et al. (2014): Diclophenac potassium versus cephtazidime for reduction of post ERCP pancreatitis in average risk patients-randomised controlled trial- interim analysis. Pancreatology, 14 (3): S22.

32. Cote G, Sagi S, Schmidt S et al. (2013): Early measures of hemoconcentration and inflammation are predictive of prolonged hospitalization from post- endoscopic retrograde cholangiopancreatography pancreatitis. Pancreas, 42 (5): 4-850.

33. Baron T, Abu dayyeh B, Abu dayye B et al. (2012): Rectal indomethacin to prevent post-ERCP pancreatitis. N Engl J Med., 367 (3): 277-278.

34.Elmunzer B, Higgins P, Saini S et al. (2013): Does rectal indomethacin eliminate the need for prophylactic pancreatic stent placement in patients undergoing highrisk ERCP? Post hoc efficacy and cost-benefit analyses using prospective clinical trial data. Am J Gastroenterol., 108 (3): 410-415. 